\title{
Topical Lignocaine with Diltiazem or Glyceryltrinitrate for Paediatric Acute Anal Fissure: A Randomized Clinical Trial
}

${ }^{1}$ Mukhtiar Ahmed, ${ }^{2}$ Jamil Akhter Munir Ahmad, ${ }^{2}$ Muhammad Ali Sheikh, ${ }^{3}$ Tariq Latif, ${ }^{4}$ Abdul Qayyum

${ }^{1}$ Department of Paediatric Surgery, Abbottabad International Medical College, Abbottabad.

${ }^{2}$ Department of Paediatric Surgery, Shaikh Zayed Hospital, Lahore

${ }^{3}$ Department of Paediatric Surgery, Shaukat Khanum Memorial Cancer Hospital \& Research Centre, Lahore

${ }^{4}$ Department of Paediatric Surgery, Fatima Memorial Hospital, Lahore

\begin{abstract}
Introduction: Anal fissure is a common problem in children, the exact etiology of which is unknown and it mostly presents with painful defecation and bleeding per rectum. The standard treatment of anal fissure is lateral internal sphincterotomy but due to risk of fecal incontinence chemical sphincterotomy is used as alternative to surgical sphincterotomy. Aims \& Objectives: To compare the effectiveness of topical diltiazem and lignocaine with glyceryl trinitrate and lignocaine in relieving of symptoms and healing of acute anal fissure in children. Place and duration of study: This study was conducted in the Department of Paediatric Surgery, Shaikh Zayed Hospital, Lahore \& Department of Paediatric Surgery, Fatima Memorial Hospital, Lahore from September 2017 to September 2018. Material \& Methods: Total 228 children were enrolled in the study and randomly divided in group A and B, 114 children in each group. Group A received topical 2\% diltiazem cream and $2 \%$ lignocaine gel, while group B received topical $0.2 \%$ glyceryl trinitrate and $2 \%$ lignocaine gel, applied locally, twice daily. Results: There were 78(68.4\%) male children in group A and $66(57.9 \%)$ in group B. All patients completed 6 week treatment course. The symptoms and condition of the anal fissure were evaluated before start of treatment and at subsequent follow up periods. In group A 55 $(48.2 \%)$ cases completely healed by second week, while in group B, $33(28.9 \%)$ cases healed. The number of completely healed cases at 4 weeks follow up in group A and group B were $91(79.8 \%)$ and 69(60.5\%) respectively, while at week 6 follow up this rate was $95(83.3 \%)$ and $73(64.0 \%)$ respectively. Symptomatic relief in painful defecation observed in group A and group B was 74(64.9\%) and 55(48.2\%) at week 2, $95(83.3 \%)$ and $74(64.9 \%)$ at week 4 while $95(83.3 \%)$ and $77(67.5 \%)$ at week 6 in two groups respectively. Conclusion: Use of combination of topical diltiazem and lignocaine for the treatment of acute anal fissure in paediatric population is preferred over combination of glyceryl trinitrate and lignocaine.
\end{abstract}

Key words: Anal fissure, Children, Diltiazem, Glyceryl trinitrate.

\section{INTRODUCTION}

\section{A} nal fissure (AF) is a longitudinal tear in the mucosa of distal anal canal extending into the anal verge. The most common site of anal fissure is posterior midline, though it may occur anywhere in anal circumference. In females the most common location is anterior midline. ${ }^{1,2}$

The anal fissure commonly presents with painful defecation and bleeding per rectum (PR). It is confirmed by observing a tear in the anal mucosa. ${ }^{3}$ The exact etiology of anal fissure is unknown. However, it is suggested that trauma to the anal canal causes tear which fails to heal due to internal anal sphincter (IAS) spasm, creating high pressure in the anal canal leading to local ischemia of the anal mucosa. ${ }^{4}$

In the management of anal fissure, the first line of treatment is to relieve constipation (causing trauma) by increase in fluid intake, high fiber diet and stool softeners. Application of local anesthetics and warm sitz bath, also help in healing of anal fissures. ${ }^{5}$

Different pharmacological treatment options are available which include topical glyceryl trinitrate, diltiazem, botulinum toxin, bethanechol, indoramin, and nifedipine. Different studies have reported healing of anal fissure by $32 \%$ to $64 \%$ with lignocaine, $74 \%$ to $88.46 \%$ with glyceryl trinitrate and with diltiazem upto $96 \%{ }^{3,6,7,8,9} \mathrm{Klin}$ et al used 
Nifedipine (which is a calcium channel blocker) with lignocaine and anal fissure completely healed in $92.9 \%$ of their patients. ${ }^{10}$

Surgical treatment options include dilatation of internal anal sphincter, fissurectomy and lateral internal sphincterotomy (LIS), but these may cause incontinence of stool.$^{5}$ It was observed by Richard et al that internal sphincter spasm was the common finding in anal fissure. In order to overcome spasm of internal sphincter, surgery was the common option but due to fear of fecal incontinence interest in non-surgical treatment has developed. ${ }^{11}$

The current study was conducted to compare the effectiveness of combination of topical diltiazem and lignocaine with combination of glyceryl trinitrate and lignocaine in relieving of symptoms and healing of acute anal fissure in children.

\section{MATERIAL AND METHODS}

The study was a randomized clinical trial and was conducted in the Department of Paediatric Surgery, Shaikh Zayed Hospital, Lahore \& Department of Paediatric Surgery, Fatima Memorial Hospital, Lahore September 2017 to September 2018 after the approval from Institution Review Board. The estimated sample size of 228 (divided into two groups of 114 each) was calculated by using $95 \%$ confidence level, $80 \%$ power with expected healing rate of $93 \%$ and $82 \%$ in A and B group respectively. Treatments were allocated to patient at random by using lottery method.

Group A- Topical 2\% diltiazem cream and 2\% lignocaine gel.

Group B- Topical $0.2 \%$ glyceryl trinitrate cream and $2 \%$ lignocaine gel.

All preparations were prepared by a local pharmacy.

\section{Inclusion Criteria:}

Patients of both genders from 1 year to 14 years of age with acute anal fissure of less than 6-week duration, presenting in Paediatric Surgery Out Patient Department and Paediatric Emergency.

\section{Exclusion Criteria}

Patients having:

- Inflammatory bowel disease

- Perianal fistula and abscess

- Hemorrhoids

- Hirschsprung's disease

- Congenital heart disease

- Previously treated anal fissure

- Severe headache (Migraine)

- Previous anal surgery \& Anorectal malformation.
Longitudinal tear in the mucosa of distal anal canal extending to the anal verge noticed on visual inspection was labelled as anal fissure.

Partial healing was labelled when granulation tissue was noted at the site of anal fissure on follow up.

Complete healing was labelled when complete epithelialization of the mucosa at the site of anal fissure was noted on follow up.

After taking written consent, the patients were divided at random by lottery method into Group A and B for treatment. Group A received combination of topical $2 \%$ diltiazem and $2 \%$ lignocaine while Group B received combination of topical $0.2 \%$ glyceryl trinitrate and 2\% lignocaine. Individuals in each group were advised to apply the given creams of pea-sized quantity at anal margins twice daily with 4 hours interval for 6 weeks period. Follow up were made after 2, 4 and 6 weeks of treatment.

Along with local application it was advised to increase fluid intake, stool softeners and sitz baths in both the groups to treat and prevent constipation. Constipation was treated aggressively in patients of both groups so that it did not affect our results. Success indicator for both groups was the complete healing of anal fissure and relief of symptoms.

\section{Statistical analysis:}

Data was analyzed by using SPSS 20.0. Quantitative data like age, duration of painful defecation, duration of bleeding frequency were described by using mean \& SD for two groups. Comparison between two groups for these variables was made by using independent sample t-test.

Qualitative data like gender, location of fissure, painful defecation, bleeding per rectum, bleeding frequency per week at enrolment were all described by using frequency and percentages for two groups, and comparisons between two groups were made by using chi-square test. P-value $\leq 0.05$ was considered statistically significant.

\section{RESULTS}

The study included 228 children with Anal Fissure (AF). These children were divided into two groups of 114 each. The group A was treated with combination of topical $2 \%$ Diltiazem and $2 \%$ lignocaine and group B with combination of Topical $0.2 \%$ Glyceryl trinitrate and $2 \%$ lignocaine. The results were observed after 2, 4 and 6 week time.

There were $78(68.4 \%)$ male children in group A and 66 (57.9\%) in group B with P value of 0.099 , (Table-1). The mean age for both groups was almost same with $P$ value of 0.890 . The number of children with AF located posteriorly in group A were 94 
$(82.5 \%)$ wile in group B were $71(62.3 \%)$. The children in group B had significantly higher number of fissures in anterior location $(37.7 \%)$ vs $(17.5 \%)$ as compared to group A with $\mathrm{P}$ value of 0.001 (Table-1).

Painful defection was also significantly higher in children in treatment group B with P-value 0.016. (Table-1)

The duration for painful defecation in group A was $14.34 \pm 7.74$ days while in group B was $12.36 \pm$ 7.17 days, with p-value 0.054 .

Bleeding per rectum was found similar in both groups. (Table-1)

The average duration of bleeding at presentation in group A was $11.83 \pm 8.41$ days while $8.06 \pm 5.61$ days in group B, and the difference was statistically significant.

Symptomatic relief in painful defecation observed in group A and group B was $74(64.9 \%)$ and 55 $(48.2 \%)$ at week 2, $95(83.3 \%)$ and $74(64.9 \%)$ at week 4 while $95(83.3 \%)$ and $77(67.5 \%)$ at week 6 in two groups respectively. The difference in relief of pain while defecation between two groups was statistically significant with p-values $0.011,0.001$ and 0.006 at 2, 4 and 6 weeks follow up times respectively. (Table-2)

When changes in painful defecation compared between follow up times in each group, the change between 2 and 4 weeks was significant for both groups with $\mathrm{p}$-value $<0.001$. The change in group $\mathrm{B}$ was insignificant between 4 and 6 weeks with pvalue 0.375 , while in group $\mathrm{A}$ there was no symptomatic improvement in painful defecation between weeks 4 and 6 .

At start of study in group A $61(53.5 \%)$ cases had no bleeding per rectum while in group B there were 65 $(58.0 \%)$ cases without bleeding per rectum. At 2 weeks follow up the numbers increased to 86 $(75.4 \%)$ and $81(71.1 \%)$ in group A and group B respectively. At 4 weeks follow up these numbers increased to $98(86 \%)$ and $94(82.4 \%)$ and at 6 weeks follow up increased to $100(87.7 \%)$ and 101 $(88.6 \%)$ in group A and group B respectively. The difference between two groups was insignificant with p-values 0.209 and 0.245 at 4 and 6 weeks respectively, while at week 2 the p-value was 0.058 . When comparison of bleeding frequency was made between follow up times within each group, the change in group A was found significant between 2 and 4 weeks with p-value 0.001 . The McNemar was not measureable for group B at both times while for group A at week 6 .

In group A $55(48.2 \%)$ cases completely healed by second week, while in group B, $33(28.9 \%)$ cases healed. The number of completely healed cases at 4 weeks follow up in group A and group B were 91 $(79.8 \%)$ and $69(60.5 \%)$ respectively, while at week 6 follow up this rate was $95(83.3 \%)$ and $73(64.0 \%)$ respectively. (Table-3)

Within group A, the healing of AF between 2 and 4 weeks' time was significant with p-value $<0.001$ and same was the case for group B. Then between 4 and 6 weeks follow up the change in group B was significant with $\mathrm{p}$-value 0.003 , while in group $\mathrm{A}$ only four partially healed fissures converted to fully healed and no change in unhealed fissures, $\mathrm{McNemar}$ was not measureable for group A. At 6 weeks follow up $83.3 \%$ cases in group A and $67.5 \%$ patients in group B were free of symptoms and none of them had constipation.

None of the patient developed headache or itching in both the groups.

\begin{tabular}{|c|c|c|c|c|c|c|}
\hline & \multicolumn{4}{|c|}{ Group } & \multirow{3}{*}{$\begin{array}{c}\mathrm{P}- \\
\text { value }\end{array}$} \\
\hline & & \multicolumn{2}{|c|}{$\begin{array}{c}\text { Group A } \\
n=114\end{array}$} & \multicolumn{2}{|c|}{$\begin{array}{c}\text { Group B } \\
n=114\end{array}$} & \\
\hline & & $\mathrm{n}$ & $\%$ & $\mathrm{n}$ & $\%$ & \\
\hline \multirow{2}{*}{ Gender } & Male & 78 & 68.4 & 66 & 57.9 & \multirow{2}{*}{0.099} \\
\hline & Female & 36 & 31.6 & 48 & 42.1 & \\
\hline \multirow{2}{*}{$\begin{array}{c}\text { Location of } \\
\text { AF }\end{array}$} & Anterior & 20 & 17.5 & 43 & 37.7 & \multirow{2}{*}{0.001} \\
\hline & Posterior & 94 & 82.5 & 71 & 62.3 & \\
\hline \multirow{2}{*}{$\begin{array}{c}\text { Painful } \\
\text { defecation }\end{array}$} & Yes & 102 & 89.5 & 111 & 97.4 & \multirow{2}{*}{0.016} \\
\hline & No & 12 & 10.5 & 3 & 2.6 & \\
\hline \multirow{2}{*}{$\begin{array}{l}\text { Bleeding } \\
\text { PR }\end{array}$} & Yes & 53 & 46.5 & 47 & 42.0 & \multirow{2}{*}{0.493} \\
\hline & No & 61 & 53.5 & 65 & 58.0 & \\
\hline \multirow{8}{*}{$\begin{array}{c}\text { Frequency } \\
\text { of } \\
\text { bleeding } \\
\text { per week }\end{array}$} & Nil & 61 & 53.5 & 67 & 58.8 & \multirow{8}{*}{0.147} \\
\hline & 1.00 & 3 & 2.6 & 9 & 7.9 & \\
\hline & 2.00 & 25 & 21.9 & 20 & 17.5 & \\
\hline & 3.00 & 15 & 13.2 & 10 & 8.8 & \\
\hline & 4.00 & 3 & 2.6 & 4 & 3.5 & \\
\hline & 5.00 & 1 & 0.9 & 2 & 1.8 & \\
\hline & 6.00 & 0 & 0.0 & 1 & 0.9 & \\
\hline & 7.00 & 6 & 5.3 & 1 & 0.9 & \\
\hline
\end{tabular}

Table-1: Basic features of patients at the time of enrolment in both groups

\begin{tabular}{|c|c|c|c|c|c|c|}
\hline \multirow{2}{*}{$\begin{array}{c}\text { Symptomatic } \\
\text { Relief in painful } \\
\text { defecation }\end{array}$} & \multicolumn{4}{|c|}{\begin{tabular}{c} 
Group \\
Group A \\
\cline { 3 - 6 }
\end{tabular}} & \multicolumn{2}{|c|}{$\begin{array}{c}\text { Group B } \\
\text { value }\end{array}$} \\
\cline { 2 - 6 } & $\mathrm{N}$ & $\%$ & $\mathrm{~N}$ & $\%$ & \\
\hline \multirow{2}{*}{ Week 2 } & Yes & 74 & 64.9 & 55 & 48.2 & \multirow{2}{*}{0.011} \\
\cline { 2 - 6 } & No & 40 & 35.1 & 59 & 51.8 & \\
\hline \multirow{2}{*}{ Week 4 } & Yes & 95 & 83.3 & 74 & 64.9 & \multirow{2}{*}{0.001} \\
\cline { 2 - 6 } & No & 19 & 16.7 & 40 & 35.1 & \\
\hline \multirow{2}{*}{ Week 6 } & Yes & 95 & 83.3 & 77 & 67.5 & \multirow{2}{*}{0.006} \\
\cline { 2 - 6 } & No & 19 & 16.7 & 37 & 32.5 & \\
\hline
\end{tabular}

Table-2: Symptomatic relief in painful defecation observed at three follow up times in both groups 


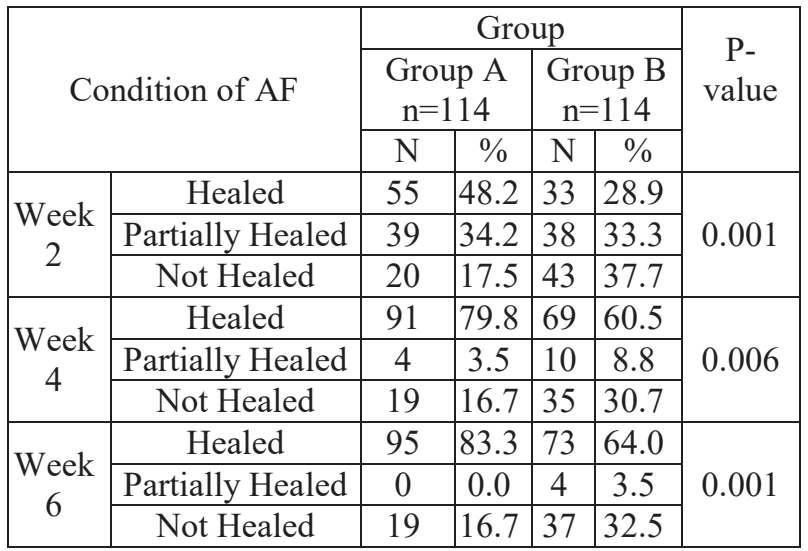

Table-3: Condition and status of fissure at three follow up times in both groups

\section{DISCUSSION}

The exact etiology of anal fissure is unknown. However, it is suggested that anal fissure may be caused by trauma to the anal canal by passage of hard stool or bouts of loose stool. Increased tone of internal anal sphincter and presence of ischemia leads to non-healing and persistence of anal fissure. ${ }^{15}$ Anorectal manometry showed fewer internal sphincter relaxations in chronic anal fissure. ${ }^{16}$

The passage of hard stool causes tear in anal mucosa that produces painful defecation and bleeding per rectum. Next time the child voluntarily holds stool to avoid another painful defecation which results in exacerbation of constipation that leads to harder stool and thus produces vicious cycle. The main stay of treatment is directed to break this vicious cycle, by blocking spasm of internal anal sphincter and relieving constipation. ${ }^{3,5,17}$

In children functional constipation due to behavioral changes has also been reported in early age group. Mother with high psychological distress and low level of education were reported as a risk factor for constipation in children. ${ }^{12}$

Different therapeutic options are available for the treatment of acute anal fissure (AAF) including chemical (pharmacological) and surgical sphincterotomy. The standard treatment is lateral internal sphincterotomy but it is invasive, requires hospitalization, spinal or general anesthesia and may cause incontinence. So chemical sphincterotomy is considered as the first option in the treatment of acute anal fissure in children. ${ }^{18}$

Half of fissures heal by increasing fluid intake, increase in fiber diet, use of stool softeners, application of local anesthetics and warm sitz baths. ${ }^{5}$.

Many studies have shown that topical glyceryl trinitrate (GTN) treatment heals AF in $40.4-68 \%$ cases and it is superior to topical lignocaine. ${ }^{11,19}$
Demirbag et al. reported $83.87 \%$ healing rate of anal fissure with 8 weeks of GTN therapy and transient fecal incontinence was reported in 1 patient. ${ }^{20}$ Side effects of topical GTN like headache, perianal dermatitis, hypotension and incontinence limits its use. ${ }^{19,21}$ Another drawback of GTN treatment of $\mathrm{AF}$ is recurrence of the fissure at the rate of $7.9 \%$ to $50 \% .^{23}$

Diltiazem (DTZ) is more effective in treating AF than GTN and relieves symptoms quickly. ${ }^{3}$ DTZ has fewer side effects as compared to GTN. ${ }^{3,18}$ Patients with AF who do not respond or who develop side effects by the use of topical nitroglycerine can be treated with DTZ, which heals AF between $50 \%-$ $92 \%$ cases. ${ }^{5}$ In other studies healing rate of AF with DTZ was observed between $67 \%$ to $89.4 \%{ }^{13,23,24}$

A large number of studies were conducted in adults comparing diltiazem and GTN, while in children most studies described the role of topical GTN, diltiazem and lignocaine individually in the treatment of acute anal fissure.

In a study by Klin et al combination of $0.2 \%$ nifedipine with lidocaine was effective in the treatment for anal fissures in children which also showed good results of healing with no side effects. ${ }^{14}$ One pilot study was conducted in Israel in which combination of calcium channel blocker (nifedipine) with lignocaine was used to treat anal fissure in children. ${ }^{10}$

In our study the incidence of AAF was higher in male children $(63 \%)$ than female $(37 \%)$ in both groups. Male to female ratio was 1.7: 1. In other studies females were slightly more than males. ${ }^{3,10}$ In the study by Cevik et al. the reported incidence of $\mathrm{AF}$ more in female was $52.7 \%{ }^{3}$

Mean age of children in our study was $4.72 \pm 2.48$ years in group A and $4.67 \pm 2.89$ years in group B, while in a study conducted by Cevik at el the mean age was 2.5 years in diltiazem group and 2 years in GTN group. ${ }^{3}$ In study conducted by Demirbag at el mean age was 3.1 year in GTN group. ${ }^{22}$ In comparison to Cevik et al. study the mean age in our study population was almost double which shows that our patients seek medical advice late.

In our study posterior anal fissures $(72.37 \%)$ were more common than anterior fissures $(27.63 \%)$. In group A $82.5 \%$ fissures were located posteriorly and $17.5 \%$ anteriorly, while in group B posterior and anterior fissures were $82.3 \%$ and $37.7 \%$ respectively. The difference in location of $\mathrm{AF}$ in our study was statistically significant ( $\mathrm{P}$ 0.001). This was confirmed by other studies in which posterior anal fissure were more common than anterior fissure. ${ }^{3,9,10} \mathrm{Klin}$ et al. reported $90 \%$ posterior anal 
fissure and around $10 \%$ anterior fissure, and Giridhar et al. reported $93.3 \%$ posterior fissure. ${ }^{9,10}$ In our study $93.4 \%$ children with AAF presented with painful defecation. In a study conducted by Cevik et al. the incidence of painful defecation in children was reported in $94.6 \%$, while in study conducted by Klin et al. painful defecation was reported in $87 \%$ cases. $^{3,10}$ Our results were comparable with results reported in literature.

In our study $37.7 \%$ of children had bleeding per rectum, Cevik et al. reported bleeding per rectum in $68.4 \%$ cases $^{3}$, while Klin et al. reported $84 \%$ cases with bleeding per rectum. ${ }^{10}$ In our study a smaller number of children presented with bleeding per rectum as compared to Cevik at el and Klin et al. studies. ${ }^{3,10}$

In our study symptomatic relief in painful defecation was observed in $83.3 \%$ and $67.5 \%$ in group A and B respectively. Klin et al. and Cevik et al. reported $83.9 \%$ and $92.9 \%$ symptomatic relief respectively. ${ }^{3,10}$ In our study relief in pain between group $\mathrm{A}$ and $\mathrm{B}$ was statistically significant ( $\mathrm{P}$ 0.006). In a study conducted by Pardan at el reported $76 \% \%$ good to excellent symptomatic relief with DTZ and $52 \%$ with GTN. ${ }^{8}$

In our study no bleeding was observed in $87.7 \%$ (group A) and $88.6 \%$ cases (group B) after completion of 6 weeks' treatment. The relief in bleeding per rectum was statistically insignificant $(\mathrm{P}$ 0.245). Cevik et al. reported $92.9 \%$ symptomatic relief with DTZ and $82.1 \%$ with GTN therapy. ${ }^{3}$

Complete healing of AF was observed in 96 $(83.3 \%)$ with DTZ and $73(64.0 \%)$ with GTN in our study. The difference was statistically significant (P 001). Cevik et al. reported a healing rate of $92.9 \%$ and $82.1 \%$ after 8 weeks of therapy with DTZ and GTN respectively. ${ }^{3,10}$

No untoward effects were observed in both of our groups after 6 weeks of treatment. Cevik et al. reported perineal dermatitis in one patient in DTZ group and one in GTN group, while no headache was observed in both groups. ${ }^{3}$ Joda et al , reported showed that GTN ointment was effective treatment for anal fissure in children, with good healing, early relief of symptoms and less side effects. ${ }^{22}$ Demirbag at el reported one case of transient fecal incontinence with GTN therapy and no headache was noted in any of the child. ${ }^{20}$ Newman et al also reported that topical diltiazem hydrochloride $(2 \%)$ or topical nifedipine $(0.2-0.5 \%)$ both proved to be effective alternatives with less side effects when compared with GTN. ${ }^{25}$ Bansal et al reported that $2 \%$ Diltiazem ointment and $.02 \%$ GTN in the treatment of chronic anal fissure, were equally effective in relieving pain, healing and recurrence, but patients treated with GTN ointment had headache. So $2 \%$ Diltiazem ointment may be preferred in the medical management of chronic anal fissure as first line of treatment. ${ }^{26}$ May be due to less duration (6 week) of treatment and as parents were also instructed not to apply GTN inside the anus to decrease systemic absorption, no side effect were observed in our study population.

The limitation of our study was that both of these creams were not available as readymade in combination with lignocaine, so there were dispensed by the pharmacy on our request.

\section{CONCLUSION}

Use of combination of topical diltiazem and lignocaine for the treatment of acute anal fissure in paediatric population is preferred over combination of glyceryl trinitrate and lignocaine or any of these drugs alone. Topical diltiazem with lignocaine can be used as $1^{\text {st }}$ line treatment in the management of acute anal fissure in children.

\section{REFERENCES}

1. Zaghiyan KN, Fleshner P. Anal fissure. Clin Colon Rectal Surg. 2011; 24(01):022-30.

2. Ayantunde AA, Debrah SA. Current concepts in anal fissures. World J Surg.2006;30(12):2246-60

3. Cevik M, Boleken ME, Koruk I, Ocal S, Balcioglu ME, Aydinoglu A, et al. A prospective, randomized, double-blind study comparing the efficacy of diltiazem, glyceryl trinitrate, and lidocaine for the treatment of anal fissure in children. Pediatr Surg Int. 2012; 28(4):411-6.

4. Katsinelos P, Kountouras J, Paroutoglou G, Beltsis A, Chatzimavroudis G, Zavos C, et al. Aggressive treatment of acute anal fissure with $0.5 \%$ nifedipine ointment prevents its evolution to chronicity. World J Gastroenterol. 2006; 12(38):6203-6.

5. Rakinic J. Anal fissure.Clin Colon Rectal Surg. 2007; 20(02):133-7.

6. Motie MR, Hashemi P. Chronic Anal Fissure: A comparative study of medical treatment versus surgical sphincterotomy. Acta Med Iran. 2016; 54(7):437-40.

7. Ahmad J, Andrabi S, Rathore M. Comparison of topical glyceryl trinitrate with lignocaine ointment for treatment of anal fissure: a randomised controlled trial.Int J Surg. 2007; 5(6):429-32.

8. Pardhan A, Azami R, Mazahir S, Murtaza G. Diltiazem vs. glyceryl tri-nitrate for symptomatic relief in anal fissure: a randomised 
clnical study. J Pak Med Assoc. 2014; 64(5):510-3.

9. Giridhar C, Babu P, Rao KS. A comparative study of lateral sphincterotomy and $2 \%$ diltiazem gel local application in the treatment of chronic fissure in ano. J Clin Diagn Res. 2014; 8(10):NC01-2.

10. Klin B, Abu-Kishk I, Efrati Y, Lotan G. Nifedipine Gel with Lidocaine in the Treatment of Anal Fissure in Children a Pilot Study and Review of the Literature. Complementary Pediatrics. 2012; 4: 53-71.

11. Nelson R. A systematic review of medical therapy for anal fissure. Dis Colon Rectum. 2004; 47(4):422-31.

12. Kilincaslan H, Abali O, Demirkaya S K, Bilci M. Clinical, psychological and maternal characteristics in early functional constipation. Pediatr Int 2014; 56: 588-93.

13. Carapeti EA, Kamm MA, Phillips RK. Topical diltiazem and bethanechol decrease anal sphincter pressure and heal anal fissures without side effects. Dis Colon Rectum. 2000; 43(10):1359-62.

14. Klin B, Efrati $\mathrm{Y}$, Berkovitch $\mathrm{M}$, et al. Anal fissure in children: a 10-year clinical experience with nifedipine gel with lidocaine. Minerva Pediatr 2016; 68: 196-200.

15. Jonas M, Scholefield JH. Anal fissure. Gastroenterol Clin North Am.2001;30(1):167-81

16. Farouk R, Duthie G, MacGregor A, Bartolo D. Sustained internal sphincter hypertonia in patients with chronic anal fissure. Dis Colon Rectum. 1994; 37(5):424-9.

17. Poh A, Tan K-Y, Seow-Choen F. Innovations in chronic anal fissure treatment: a systematic review. World J Gastrointest Surg. 2010; 2(7):231-41.

18. Hashmi F, Siddiqui FG. Diltiazem (2\%) versus glyceryl trinitrate cream $(0.2 \%)$ in the management of chronic anal fissure. J Coll Physicians Surg Pak. 2009; 19(12):750-3.

19. Knight J, Birks M, Farouk R. Topical diltiazem ointment in the treatment of chronic anal fissure. Br J Surg. 2001; 88(4):553-6.

20. Demirbag S, Tander B, Atabek C, Surer I, Öztürk H, Cetinkursun S. Long-term results of topical glyceryl trinitrate ointment in children with anal fissure. Ann Trop Paediatr. 2005; 25(2):135-7.

21. Tankova L, Yoncheva K, Kovatchki D, Doytchinova I. Topical anal fissure treatment: placebo-controlled study of mononitrate and trinitrate therapies.Int J Colorectal Dis. 2009; 24(4):461-4.

22. Joda AE, Al-mayoof AF. Efficacy of nitroglycerine ointment in the treatment of pediatric anal fissure. J Pediatr Surg 2017; 52:1782-6.

23. Kocher H, Steward M, Leather A, Cullen P. Randomized clinical trial assessing the side-effects of glyceryl trinitrate and diltiazem hydrochloride in the treatment of chronic anal fissure. Br J Surg. 2002; 89(4):413-7.

24. Jonas M, Speake W, Scholefield JH. Diltiazem heals glyceryl trinitrate-resistant chronic anal fissures. Dis Colon Rectum. 2002;45(8):1091-5.

25. Newman M, Collie M. Anal fissure: diagnosis, management, and referral in primary care. $\mathrm{Br} \mathrm{J}$ Gen Pract. 2019; 69(685): 409-410.

26. Bansal A. R., Pawan Kumar Yadav, Rajesh Godara, Noresh Pal, Rathindra Tripura, Jaikaran. Comparative evaluation of $0.2 \%$ glyceryl trinitrate vs. $2 \%$ diltiazem ointment in treatment of chronic anal fissure: a case trial. Hellenic Journal of Surgery 2016; 88: 25-30.

\section{The Authors:}

Dr. Mukhtiar Ahmed

Senior Registrar,

Department of Paediatric Surgery,

Abbottabad International Medical College,

Abbottabad.

Dr. Jamil Akhter Munir Ahmad

Senior Registrar,

Department of Paediatric Surgery,

Shaikh Zayed Hospital, Lahore.

Prof. Muhammad Ali Sheikh

Head, Department of Paediatric Surgery,

Shaikh Zayed Hospital, Lahore.

Prof. Tariq Latif

Consultant Paediatric Surgeon,

Department of Paediatric Surgery,

Shaukat Khanum Memorial Cancer Hospital,

Lahore.

Dr. Abdul Qayyum

Senior Registrar,

Department of Paediatric Surgery,

Fatima Memorial Hospital, Lahore.

\section{Corresponding Author:}

Dr. Jamil Akhter Munir Ahmad

Senior Registrar,

Department of Paediatric Surgery,

Shaikh Zayed Hospital, Lahore.

E-mail: doctorjamil@yahoo.com 